\title{
Psychometric evaluation of a newly developed Elderly- Constipation Impact Scale
}

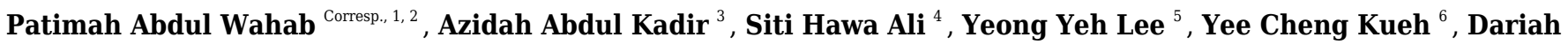 \\ Mohd Yusoff ${ }^{2}$ \\ 1 Department of Medical-Surgical Nursing, Kulliyyah of Nursing, International Islamic University Malaysia, Kuantan, Pahang, Malaysia \\ 2 Programme of Nursing, School of Health Sciences, Universiti Sains Malaysia, Kota Bharu, Kelantan, Malaysia \\ 3 Department of Family Medicine, School of Medical Sciences, Universiti Sains Malaysia, Kota Bharu, Kelantan, Malaysia \\ 4 Unit of Interdisciplinary Health Sciences, School of Health Sciences, Universiti Sains Malaysia, Kota Bharu, Kelantan, Malaysia \\ 5 Department of Medical, School of Medical Sciences, Universiti Sains Malaysia, Kota Bharu, Kelantan, Malaysia \\ 6 Unit of Biostatistics and Research Methodology, School of Medical Sciences, Universiti Sains Malaysia, Kota Bharu, Kelantan, Malaysia \\ Corresponding Author: Patimah Abdul Wahab \\ Email address: patimah@iium.edu.my
}

Background. Chronic constipation is a common symptom among the elderly and it may affect their quality of life (QoL). A lack of available research focused on the elderly means that this effect is not well understood. This study aimed to develop and validate a new scale (Elderly-Constipation Impact Scale [E-CIS]) to measure the impact of chronic constipation on QoL among the elderly. Methods. A pool of items was generated from a qualitative study, literature reviews, and expert reviews. Exploratory factor analysis (EFA) was performed on the original 40 items of the E-CIS and followed by 27 items for confirmatory factor analysis (CFA). A total of 470 elderly people with chronic constipation were involved. Results. The mean age of the participants was $68.64 \pm 6.57$. Finally, only 22 items were indicated as appropriately representing the E-CIS, which were grouped into seven subscales: 'daily activities', 'treatment satisfaction', 'lack of control of bodily function', 'diet restriction', 'symptom intensity', 'anxiety' and 'preventive actions'. The scale was confirmed as valid (root mean square error of approximation [RMSEA] $=0.04$, comparative fit index $[\mathrm{CFI}]=0.961$, Tucker-Lewis index $[\mathrm{TLI}]=0.952$ and chisquare/degree of freedom $[\mathrm{chiSq} / \mathrm{df}]=1.44)$ and reliable (Cronbach's alpha: $0.66-0.85$, composite reliability $[C R]=0.699-0.851$ ) to assess the impact of chronic constipation on the elderly's QoL. Conclusions. The E-CIS is useful to measure the impact of chronic constipation on the elderly's QoL. A further test is needed to determine the validity and reliability of this scale in other elderly population. 


\section{Psychometric evaluation of a newly developed EIderly- Constipation Impact Scale}

Patimah Abdul Wahab ${ }^{1,2}$, Azidah Abdul Kadir ${ }^{3}$, Siti Hawa Ali ${ }^{4}$, Yeong Yeh Lee ${ }^{5}$, Yee Cheng Kueh $^{6}$, Dariah Mohd Yusoff ${ }^{2}$

${ }^{1}$ Department of Medical-Surgical Nursing, Kulliyyah of Nursing, International Islamic University Malaysia, Kuantan, Pahang, Malaysia

${ }^{2}$ Programme of Nursing, School of Health Sciences, Universiti Sains Malaysia, Kota Bharu, Kelantan, Malaysia

${ }^{3}$ Department of Family Medicine, School of Medical Sciences, Universiti Sains Malaysia, Kota Bharu, Kelantan, Malaysia

${ }^{4}$ Unit of Interdisciplinary Health Sciences, School of Health Sciences, Universiti Sains Malaysia, Kota Bharu, Kelantan, Malaysia

${ }^{5}$ Department of Medical, School of Medical Sciences, Universiti Sains Malaysia, Kota Bharu, Kelantan, Malaysia ${ }^{6}$ Unit of Biostatistics and Research Methodology, School of Medical Sciences, Universiti Sains Malaysia, Kota Bharu, Kelantan, Malaysia

Corresponding Author:

Patimah Abdul Wahab ${ }^{1,2}$

Email address: patimah@,iium.edu.my 


\section{Abstract}

36 Background. Chronic constipation is a common symptom among the elderly and it may affect

37

38

39

40

41

42

43

44

45

46

47

48

49

50

51

52

53

54

55

56

57

58

59

60

61

62

63

64

65

66

67

68

69

70

71

72

their quality of life (QoL). A lack of available research focused on the elderly means that this effect is not well understood. This study aimed to develop and validate a new scale (ElderlyConstipation Impact Scale [E-CIS]) to measure the impact of chronic constipation on QoL among the elderly.

Methods. A pool of items was generated from a qualitative study, literature reviews, and expert reviews. Exploratory factor analysis (EFA) was performed on the original 40 items of the E-CIS and followed by 27 items for confirmatory factor analysis (CFA). A total of 470 elderly people with chronic constipation were involved.

Results. The mean age of the participants was $68.64 \pm 6.57$. Finally, only 22 items were indicated as appropriately representing the E-CIS, which were grouped into seven subscales: 'daily activities', 'treatment satisfaction', 'lack of control of bodily function', 'diet restriction', 'symptom intensity', 'anxiety' and 'preventive actions'. The scale was confirmed as valid (root mean square error of approximation $[\mathrm{RMSEA}]=0.04$, comparative fit index $[\mathrm{CFI}]=0.961$, Tucker-Lewis index $[\mathrm{TLI}]=0.952$ and chi-square/degree of freedom $[\mathrm{chiSq} / \mathrm{df}]=1.44$ ) and reliable (Cronbach's alpha: $0.66-0.85$, composite reliability $[\mathrm{CR}]=0.699-0.851$ ) to assess the impact of chronic constipation on the elderly's QoL.

Conclusions. The E-CIS is useful to measure the impact of chronic constipation on the elderly's QoL. A further test is needed to determine the validity and reliability of this scale in other elderly population.

\section{Introduction}

Constipation occurs frequently among the elderly and its prevalence may be as high as $20 \%$ of community-dwelling elderly people and $74 \%$ of nursing home residents (Bouras \& Tangalos, 2009). It is a symptom-based disorder of the gastrointestinal system which refers to a condition of having difficulties in bowel opening or infrequent passage of stool, hard stool, or a feeling of incomplete evacuation (Bharucha, Pemberton \& Locke, 2013). Previous studies showed that constipation may cause a considerable impact on quality of life (QoL) and functional status, as well as being a significant driver of healthcare costs (Dennison et al., 2005; Nellesen et al., 2013; Pinto Sanchez \& Bercik, 2011; Shalmani et al., 2011; Sun et al., 2011). The impact of constipation on QoL is usually predominated by mental health, and the magnitude of the impact is comparable to other diseases (Belsey et al., 2010). This impact is more obvious among the elderly with persistent or chronic conditions and the presence of abdominal pain or discomfort (Johanson \& Kralstein, 2007; Jun et al., 2006; Koloski et al., 2013).

The impact of constipation on the elderly's QoL is usually measured using constipationspecific of generic instruments. The use of generic instruments is limited in terms of comparing the impact on QoL of those with and without constipation, but the constipation-specific instrument allows the detection of the specific impact of constipation on QoL. So far, there is one

PeerJ reviewing PDF | (2019:08:40705:1:0:CHECK 19 Dec 2019) 


\section{3}

104

105

106

107

108

109

110

111

main constipation QoL scale (Patient Assessment of Constipation Quality of Life [PAC-QoL]) with psychometric validity and reliability available for the elderly population (Frank, Flynn \& Rothman, 2001; Marquis et al., 2005). However, its usage is not suitable for the elderly because the impact is measured based on five items under the satisfaction domain, and the scale was validated only on the feasibility of the interview format among 24 nursing home residents with chronic constipation.

The existing constipation QoL scales also differ in terms of the domains measured. For example, Szeinbach et al. (2009), focused only on patients' satisfaction with the treatment because of its closed relationship with the other domains like daily life activity and psychosocial domains. In contrast to this, Wang et al. (2009), argued that the satisfaction domain is more likely to measure symptom severity, while the physical domain is not measuring the impact of chronic constipation on daily life activity. Based on the revised Wilson and Cleary model of health-related quality of life (HRQoL), an individual's constipation-QoL is influenced by the individual's characteristics, environment, biological function, symptoms, functional status, general health perceptions and overall QoL (Ferrans et al., 2005; Bakas et al., 2012).

Patimah and colleagues (2017) emphasized that the existing constipation-QoL scales were developed in Western countries and, thus, they have lack of cultural sensitivity and reference to issues of age. Most of the domains and items measured such as work/leisure, psychosocial or social impairment, and treatment satisfaction refer to Western cultures and lifestyles which are unsuitable for other populations, particularly elderly residents of Asian countries. A good scale should be developed based on the importance of the domains measured to the study population and the impact of symptoms as defined by the patient (Byrne et al., 2002; Damon, Dumas \& Mion, 2004; Nilsson,Parker \& Kabir, 2004). Thus, this study aimed to develop and validate a culturally sensitive scale - the Elderly Constipation Impact Scale (E-CIS)

- with the purpose of assessing the impact of chronic constipation on QoL among elderly people, regardless of treatments they received or practised. In this study, we used the World Health Organization definition "a state of complete physical, mental, and social well-being not merely the absence of disease or infirmity" (International Health Conference, 2002) to define the impact of chronic constipation on health related QoL.

\section{Materials \& Methods}

\section{Sample}

The sample of this study was elderly with chronic constipation living in community settings of states of Terengganu and Kelantan. They were defined based on Malaysia's National Policy for Older Persons, which is an individual age 60 years old and above (Ministry of Women Family and Community Development, 2011). The criteria for inclusion were that participants must be men or women, who had lived in the community for at least 12 months and were able to understand Malay language (spoken in the local dialect). The criteria for exclusion were cognitive impairment - as determined by the elderly cognitive assessment questionnaire (ECAQ) 
112 (Kue \& Ko, 1992, 1995), hospitalization, significant hearing impairment, stoma, and

113 gastrointestinal cancers. These eligibility criteria were applied to participants for all phases.

114 For diagnosis of chronic constipation, the elderly participants were asked the following

115 question: 'Do you have constipation for the past three months?', and, if they answered 'Yes',

116 they were asked to rate the level of severity based on a 5-point Likert scale $(1=$ not severe to $5=$

117 very severe). Respondents with constipation for the past three months, with a severity level of at

118 least 'slightly severe', were invited to participate in the study. The aim was to involve a

119 heterogeneous population that allowed for the detection of differences in scores across the new

120 scale (Marquis et al., 2005; Szeinbach et al., 2009). General health status was measured by

121 asking the participants to rate their current perception on health status using a 5-point Likert

122 scale between poor and very good.

123 The participants were recruited from two community settings: Terengganu in Phase 2 and

124 Kelantan in Phase 3 of the study. A random cluster sampling to eight districts of Terengganu

125 resulted in the elderly living in community setting in the district of Marang were selected. In

126 Kelantan, purposive sampling was used to recruit the participants by using the homogenous

127 sampling method (Etikan, Musa \& Alkassim, 2016). They were among those who attended a

128 family medicine specialist clinic in a teaching hospital situated in Kelantan.

129 The total sample size of this study was 470 participants. In Phase 2, the sample size of

130200 was derived based on a five participants per item ratio (Anthoine et al., 2014). Another

131 group of elderly people were then recruited in Phase 3 with the sample size of 270, which was

132 calculated based on the ratio of 10 participants to one item (Fabrigar \& Wegener, 2012;

133 Nunnally, 1978).

\section{Data assessment}

135 The E-CIS was developed and validated in three phases: a) items generation (Phase 1); b) items 136 reduction and establishment of factor structure (Phase 2), and; c) confirmation of the factor

137 structure and items (Phase 3). Meanwhile, its reliability was examined in the last two phases

138 (Fig. 1). Findings of Phase 1 was used to generate initial items for the new scale. Following this,

139 two cross-sectional studies were carried out among the elderly of a community setting in

140 Terengganu and Kelantan from October 2015 to July 2016 to evaluate its psychometric property.

141 A set of questionnaires consisting of socio-demographic data and items of the new scale were

142 completed. In Phase 2, a face-to-face interview from door-to-door was conducted by an

143 investigator and a research assistant (PAW \& NFR) to prevent incomplete data. A similar

144 approach of data collection was applied by the similar researcher in Phase 3 to avoid bias. The

145 study involving human participants has obtained ethical approval from the Research Ethics

146 Committee (Human), Universiti Sains Malaysia (USM/JEPeM/272.3. [1.7]). Permission to

147 conduct the study was granted by the headmen and hospital director. Prior to data collection,

148 verbal and written consents were obtained from the participants.

149

150 Items Generation 
151 An initial pool of items was generated based on inputs from three sources that consisted of data

152 from semi-structured interviews, comprehensive literature reviews, and opinions from an

153 interdisciplinary group of experts. Data of semi-structured interviews were derived from a

154 previously published study by the same group of investigators (Patimah et al., 2017). Initially,

155 relevant codes from interviews were rereviewed to form items using layman descriptors in the

156 standard Malay language. Crosschecking of these codes with literature reviews produced 74

157 items (Marquis et al., 2005; Bowling \& Stenner, 2011).

158 To ensure content validity, all 74 items were reviewed by an expert panel that consisted

159 of two nurses, two medical doctors, two lecturers, and one researcher (DMY, AFI, LYY, AAK,

160 SHA, MSBY, \& IIH). In addition, decisions to delete or to retain items were guided by the

161 content validity index (CVI), an index based on the aggregated ratings of a panel of experts

162 (Polit \& Beck, 2006). The recommended minimum CVI for scale (S-CVI) is 0.80 and for

163 individual items (I-CVI) is 0.78 (Polit \& Beck, 2006, 2012). For E-CIS, the S-CVI was 0.77 and

164 I-CVI ranged 0.40 to 1.00 . Subsequently, items with low I-CVI were either removed or revised

165 and, at the end of this process, 43 of 74 items remained. Next, the remaining 43 items and their

166 responses (visual analogue scale and Likert scale) were checked for wording, content,

167 appropriateness and convenience by two elderly people with chronic constipation (IM \& RY).

168 The 43-item questionnaire was then pre-tested on another 20 elderly people with chronic

169 constipation recruited via a face-to-face approach in an informal educational center. A debriefing

170 interview was conducted, where they were asked to complete the questionnaire and they were

171 then asked to explain their understanding of the items using their own words. They were also

172 asked to comment and provide suggestions on the instructions and contents of the questionnaire.

173 After this process, three items were removed, and 40 items were further examined for their factor

174 structure.

175 To summarize, the first version of E-CIS has 40 items of 5-point Likert scale. Responses

176 on impact are measured based on frequency of experience, where $1=$ never or very rare and $5=$

177 always. In these items, a higher score indicates a greater impact of chronic constipation on QoL

178 of the elderly person. On the other hand, four items are rated based on the level of agreement to

179 their treatment satisfaction, with values ranging from $1=$ strongly disagree to $5=$ strongly agree.

180 These are reversed coded items. The total score is determined as a percentage by summating the

181 scores per the total score and multiplying by 100.

182

183 Item reduction and establishment of factor structure

184 Phase 2 was an exploratory factor analysis (EFA) to further reduce irrelevant items and to

185 establish a factor structure. Principal axis factoring with promax rotation extraction was applied

186 to explore the structure within the data as a basis for removal of redundancy or unnecessary

187 items. The number of factors was determined based on the scree plot, eigenvalues greater than

188 1.0, and that they met the variance criterion of higher than 60\% (Hair et al., 2010). The items

189 were retained for further analysis if they obtained the ideal communality value of 0.3 and higher

190 and had factor loadings of 0.3 and higher on one factor without extensive cross-loadings on other 
191 factors (Hair et al., 2010; Child, 2006). A low communality value and low factor loadings

192 indicate the failure of items to represent its factor satisfactorily (Hair et al., 2010; Fabrigar \&

193 Wegener, 2012).

194

\section{Confirmation of the factor structure and items}

196 Confirmatory factor analysis (CFA) was carried out in the last phase of this study. The CFA was performed using the analysis of moment structure (AMOS) software version 21 (SPSS Inc., Chicago, US) to assess the fitness of the factor structure. Four types of fitness indexes were used to assess the goodness of fit: root mean square error of approximation (RMSEA) of $<0.08$, comparative fit index (CFI) and Tucker-Lewis fit index (TLI) of $>0.90$, and chi-square/degrees of freedom (chisq/df) of $<3.0$ (Zainudin, 2014, 2015). The factor structure of E-CIS was fit, and the construct validity was achieved, if the model met the fitness indexes' required levels. The

203 modification index (MI) was used to guide model modification because the emphasis on content of the construct above model fit adjustments was necessary, especially when our main research objective was scale development (Hair et al., 2010; DeVellis, 2012).

206

207

208

\section{Data and statistical analysis}

Frequency or mean was used for descriptive data where appropriate. The construct validity of the new scale was examined firstly by EFA, followed by CFA - as described in above sections. Pairwise deletion for correlations, the listwise exclusion for the EFA, and full estimation maximum likelihood estimation in the CFA were used to handle the missing data. In addition, convergent validity and reliability were also assessed, as described below. (AVE) for every construct. The validity was achieved when all of the AVE values exceeded 0.50 (Zainudin, 2014, 2015). Having less than that would indicate more errors have remained in the items than the variance explained by the latent factor structure (Hair et al., 2010). The AVE value was also used to assess the discriminant validity of the new scale. The validity of respective construct was achieved if the square root of its AVE exceeded its correlation value with other constructs in the model (Zainudin, 2014, 2015).

The new scale's reliability was evaluated using internal consistency and composite reliability (CR), both performed after EFA and CFA. Cronbach's alpha value of 0.70 to 0.90 indicates a satisfactory level of internal consistency (Zainudin, 2014, 2015) but, for exploratory research such as ours, 0.60 was preferable (Hair et al., 2010; Kline, 2010). In the EFA, the internal consistency of each factor was examined to improve the total score reliability. An item was to be eliminated if removal of that item would improve item-to-total correlation. A similar method was utilized to assess internal consistency in CFA to ensure a good fit model was obtained. The $\mathrm{CR}$ was used to indicate the reliability and internal consistency of a latent construct. The minimum threshold value for $\mathrm{CR}$ was 0.6 , a higher value indicates better reliability (Zainudin, 2014, 2015; Fornell \& Larcker, 1981). 


\section{Results}

232 A total of 470 elderly with chronic constipation from various community settings in Kelantan

233 and Terengganu participated in the study. Out of these, 200 of the participants were from Phase 2

234 of the study and 270 from Phase 3. The age was between 60 and 100 years old, with a mean age

235 of $68.64 \pm 6.57$. All participants were Muslims with more women than men (53.6 vs. 46.4\%).

236 Table 1 shows the background of the participants of this study.

237

238

239

240

241

242

243

244

245

246

247

248

249

250

251

252

253

254

255

256

257

258

259

260

261

262

263

264

Validity

From EFA, the initial 40 items were extracted into eight factors and this accounted for $61.0 \%$ of the cumulative variance. Subsequently, 27 items were maintained, and 13 items were removed. The Cronbach's alpha for the 27 items was 0.80 . The removed items were redundant items that were highly intercorrelated, possess a communality value of less than 0.3 , not identifiable with primarily one factor, and the deleted item improved internal consistency reliability (Child, 2006; Hair et al., 2010). Table 2 shows the remaining items after EFA and the values of its factor loadings, communality, item-total correlation, Cronbach's alpha if an item was deleted, and the Cronbach's alpha of each.

Application of CFA to establish the fitness of the measurement model obtained from the EFA implied that the first version of E-CIS has a poor fit. This was illustrated by indexes RMSEA $=0.076, \mathrm{CFI}=0.799, \mathrm{TLI}=0.761$, and chisq $/ d f=2.566$. Subsequent modifications to the EFA model resulted in seven factors and 22 items (Fig. 2). Five items were removed due to low factor loadings ( 0.17 and below). Factors of dietary fiber and fluid intake were justified as a single factor and named as "preventive actions". The revised CFA version was a good model fit, as shown by indexes RMSEA $=0.04, \mathrm{CFI}=0.961$, TLI $=0.952$, and chisq $/ d f=1.44$.

The factors and items in the final E-CIS were daily activities (four items), treatment satisfaction (four items), lack of control of bodily function (three items), diet restriction (two items), symptom intensity (two items), anxiety (four items), and preventive actions (three items) (Table 3). The AVE value for all items ranged from 0.53 to 0.61 , which exceeded their minimum threshold values. The AVE analysis indicated that all items were statistically significant for the measurement model and were free from redundancy, therefore achieving convergent validity. The square root of AVE for each construct had exceeded its correlation value with the other constructs in the model, thus confirming discriminant validity.

\section{Reliability}

Cronbach's alpha of the final E-CIS was 0.78 and the value for all subscales ranged from 0.66 to

266 0.85. Specifically, the Cronbach's alpha value for each subscale is as follows: daily activities

267 $(0.85)$, treatment satisfaction $(0.82)$, lack of control of bodily function $(0.78)$, diet restriction

268 $(0.66)$, symptom intensity $(0.76)$, anxiety $(0.81)$ and preventive actions $(0.83)$. The CR values for

269 all the constructs ranged from 0.70 to 0.85 . These results indicated that the new scale was accurate and reliable.

270 


\section{Discussion}

272 Seven factors were identified to have impacted QoL and were further simplified into a 22-item

273 scale, taking into consideration the needs and values of elderly people and their families (Bakas

274 et al., 2010). Based on factor analysis, these factors were 'daily activities', 'treatment

275 satisfaction', 'lack of control of bodily function', 'diet restriction', 'symptom intensity',

276 'anxiety', and 'preventive actions'. The factors identified in this study were also similar to the

277 irritable bowel syndrome (IBS)-specific QoL. Included among them were illness experience,

278 stressors, coping mechanisms and psychological state (Wong \& Drossman, 2010).

279 In the context of a chronic and complex disorder such as constipation, improvement in

280 health-related QoL is often considered a paramount treatment outcome for the elderly, and

281 therefore it is pertinent to first understand the impact of this disorder (Pinto Sanchez \& Bercik,

282 2011; Belsey et al., 2010). The current study indicates that the newly developed E-CIS is a valid,

283 reliable and specific tool for elderly people to evaluate the impact of chronic constipation on

284 their QoL.

285

286

287

288

289

290

291

292

293

294

295

296

297

298

299

300

301

302

303

304

Although there are several QoL scales for chronic constipation, none fulfilled all the criteria needed to evaluate the impact of this disorder in elderly people (Marquis et al., 2005; Szeinbach et al., 2009; Wang et al., 2009). Firstly, these existing scales were not specifically developed or validated for the elderly population, and it is known that the elderly engage in very different behaviors from the younger population. Secondly, other local or cultural factors such as religion and dietary intake were not included in these scales, but these factors were found to be especially important for the elderly Malaysian population, as reported in a qualitative study (Patimah et al., 2017).

The factor of 'preventive action' in E-CIS was important to the elderly - especially the intake of water, fruits, and vegetables. This factor, in addition to factor of 'diet restriction' was a newly identified factor associated with the effect of constipation on QoL. However, previous studies have reported on these factors in other gastrointestinal disorders such as the 'coping/behavior' factor in Fecal Incontinence Quality of Life (FIQoL) (Hashimoto et al., 2010; Kunduru et al., 2015; Rockwood et al., 2000).

'Treatment satisfaction', as factor or an item, is a common inclusion in many constipation-related scales (Li, Lee \& Suen, 2014; Müller-lissner et al., 2010; Müller-lissner et al., 2013; Nour- Eldein et al., 2014). Earlier QoL scales had a 'satisfaction' subscale, but items were heterogeneous and based on frequency and regularity in bowel movements, activities, expectations, values, effectiveness and treatment satisfaction (Marquis et al., 2005; Szeinbach et al., 2009). In newly developed E-CIS, the 'treatment satisfaction' subscale focused on

305 satisfaction with the utilization and effectiveness of an unspecified treatment.

In our study, there are three items reflecting fear in factor 'anxiety'. Kalat (2014) had

307 differentiated between fear and anxiety by asserting that fear is an individual's response to an

308 immediate danger, whereas anxiety is their vague sense that 'something bad might happen'.

309 Based on this understanding, we identified that the three items reflected the elderly's fear emotion because the responses were focussed on a specific condition. However, we labelled 
311 these items as 'anxiety' factor because of the response to different conditions due to an unknown

312 or poorly defined threat.

313 In the new scale, the item associated with the effect of constipation on worship activities

314 was identified under the subscale of 'daily activities'. We have shown in our published

315 qualitative study that prayer or worship, a daily practice for many elderly people, was often

316 disturbed because of constipation (Patimah et al., 2017). Studies have shown that, in later life,

317 religiosity is a well-documented coping strategy in terms of improvements to psychological well-

318 being (Momtaz, Hamid \& Yahaya, 2009; Momtaz et al., 2010).

319 The items of this new scale were developed and validated based on a qualitative study

320 using the grounded theory approach (Patimah et al., 2017). Besides, the content and face validity

321 of these items were supported by extensive literature reviews and experts' opinions. All the

322 measured items were well loaded to its constructs. This was evidenced by the ideal estimate for

323 standardized loading of 0.7 that was shown for most items in the CFA results (Hair et al., 2010).

324 Two items with factor loadings of 0.55 and 0.59 and two items with R-square of 0.3 and 0.34

325 were retained. According to the rule of thumb, these values are accepted when the main research

326 objective is scale development (DeVellis, 2012; Hair et al., 2010). Moreover, the model achieved

327 the required level of the fitness indices and the new 22-item E-CIS has been shown to have good

328 discriminant validity and convergent validity. These findings suggest that the items represent the

329 effect of constipation on the QoL of the elderly satisfactorily.

330 Calculation of the E-CIS score could be in the form of the total mean score or the total

331 mean subscale scores. Each subscale score provides additional information about individual

332 factors that affect the impact of constipation, compared to a single score. The minimum total

333 score is 20 (very low impact on QoL) and the maximum is 100 (very high impact on QoL). This

334 baseline value is obtained by dividing the minimum and maximum total scores of 22 items by

335110 , which is the maximum score of the scale. The values are then multiplied by 100 to find the

336 percentage.

337 The new scale is reliable based on its internal reliability and CR of 0.7 and above

338 (DeVellis, 2012). In many studies on scales validation, only a limited number of measures in the construct validity or reliability were reported (Szeinbach et al., 2009; Wang et al., 2009). In our study, we performed most - if not all - of the validity and reliability assessments, also including EFA and CFA. The reason was that we aimed to have a more comprehensive evaluation of the new scale, but also to have the highest minimum number of items which will suit elderly respondents in our culture better.

Several limitations to this study were identified. The E-CIS was specifically made for elderly people without cognitive impairment - which is a common condition among the elderly. The results on validity and reliability indicated by this scale were not tested with the existing validated and reliable scales, and its sensitivity is not tested by pre and post-treatment. Out of seven factors of the E-CIS, there are two factors, namely 'diet restriction' and 'symptoms intensity' that have only two items. It is generally accepted to have two items per factor or subscale, but the interpretation of results based on the subscale score should be performed 
351 cautiously (Chan et al., 2010; Tabachnick \& Fidell, 2007). Other than that, the scale is measured

352 using a 5-point Likert scale to produce the mean score. According to Chua (2008), treating the

353 Likert scale as an interval scale may lead to bias because the mean score tends to accumulate to

354 the middle value. These limitations should be kept in mind when assessing the impact of chronic

355 constipation on the elderly's QoL using this scale.

\section{Conclusions}

357 The E-CIS is a constipation-specific QoL scale, which in this study was written in the standard

358 Malay language. This multidimensional scale consists of 22 items with seven subscales. It is

359 proven to be valid and reliable in assessing the impact of chronic constipation on the elderly's

360 QoL among the Malays in Kelantan, regardless of the type of treatment that they have practiced

361 or received. However, further validation study is required in other elderly populations and other

362 ethnic groups to confirm its robustness for multi-ethnic or multinational studies.

\section{Acknowledgements}

364 The authors would like to acknowledge Associate Professor Dr Muhamad Saiful Bahri Yusoff,

365 Ms Fairuza Syahira Zainuddin, and all the experts, who provided constructive comments and

366 insights, and to the research assistant who helped in data collection.

\section{References}

1. Anthoine E, Moret L, Regnault A, Sébille V, Hardouin JB. 2014. Sample size used to validate a scale: A review of publications on newly-developed patient reported outcomes measures. Health and Quality of Life Outcomes, 12(176).

371

372

373

374

375

376

377

378

379

380

381

382

383

384

385

386

387

388

2. Bakas T, McLennon SM, Carpenter JS, Buelow JM, Otte JL, Hanna KM, Ellett ML, Hadler KA, Welch JL. 2012. Systematic review of health-related quality of life models. Health and Quality of Life Outcomes, 10(134).

3. Belsey J, Greenfield S, Candy D, Geraint M. 2010. Systematic review: Impact of constipation on quality of life in adults and children. Alimentary Pharmacology \& Therapeutics, 31(9), 938-49.

4. Bharucha AE, Pemberton JH, Locke GR. 2013. American Gastroenterological Association technical review on constipation. Gastroenterology, 144(1), 218-38.

5. Bouras EP, Tangalos EG. 2009. Chronic constipation in the elderly. Gastroenterology Clinics of North America, 38(3), 463-80.

6. Bowling A, Stenner P. 2011. Which measure of quality of life performs best in older age?: A comparison of the OPQOL, CASP-19 and WHOQOL-OLD. Journal of Epidemiology \& Community Health, 65(3), 273-80.

7. Byrne CM, Pager CK, Rex J, Roberts R, Solomon MJ. 2002. Assessment of quality of life in the treatment of patients with neuropathic fecal incontinence. Diseases of the Colon \& Rectum, 45(11), 1431-6.

8. Chan Y, Ching JYL, Cheung CMY, Tsoi KKF, Polder-Verkiel S, Pang SHY, Quan WL, Kee KM, Chan FKL, Sung JJY, Wu JCY. 2010. Development and validation of a 
disease-specific quality of life questionnaire for gastro-oesophageal reflux disease: The GERD-QOL questionnaire. Alimentary Pharmacology and Therapeutics, 31(3), 452-60.

9. Child D. 2006. The essentials of factor analysis (3rd ed.). New York: Continuum.

10. Chua YP. 2008. Basic statistics in research: Ordinal and nominal scale data analysis. Kuala Lumpur: McGrawHill Education.

11. Damon H, Dumas P, Mion F. 2004. Impact of anal incontinence and chronic constipation on quality of life. Gastroenterol Clin Biol, 28, 16-20.

12. Dennison C, Prasad M, Lloyd A, Bhattacharyya SK, Dhawan R, Coyne K. 2005. The health-related quality of life and economic burden of constipation. PharmacoEconomics, 23(5), 461-76.

13. DeVellis RF. 2012. Scale development: Theory and applications (3rd ed.). Thousand Oaks, CA: Sage Publications, Inc.

14. Etikan I, Musa SA, Alkassim RS. 2016. Comparison of convenience sampling and purposive sampling. American Journal of Theoretical and Applied Statistics, 5(1), 1-4. https://doi.org/10.11648/j.ajtas.20160501.11.

15. Fabrigar LR, Wegener DT. 2012. Exploratory factor analysis. New York: Oxford University Press.

16. Ferrans CE, Zerwic JJ, Wilbur JE, Larson JL. 2005. Conceptual model of health-related quality of life. Journal of Nursing Scholarship, 37(4), 336-42.

17. Fornell C, Larcker DF. 1981. Evaluating structural model with unobserved variables and measurement errors. Journal of Marketing Research, 18(1), 39-50.

18. Frank L, Flynn J, Rothman M. 2001. Use of a self-report constipation questionnaire with older adults in long-term care. The Gerontologist, 41(6), 778-86.

19. Hair JF, Black WC, Babin BJ, Anderson RE. 2010. Multivariate data analysis (7th ed.). Upper Saddle River, NJ: Pearson Prentice Hall.

20. Hashimoto H, Shiokawa H, Funahashi K, Saito N, Sawada T, Shirouzu K, Yamada K, Sugihara K, Watanabe T, Sugita A, Tsunoda A, Yamaguchi S, Teramoto T. 2010. Development and validation of a modified fecal incontinence quality of life scale for Japanese patients after intersphincteric resection for very low rectal cancer. $J$ Gastroenterol, 45, 928-35.

21. International Health Conference. 2002. Constitution of the World Health Organization. 1946. Bulletin of the World Health Organization, 80(12), 983-84.

22. Johanson JF, Kralstein J. 2007. Chronic constipation: A survey of the patient perspective. Alimentary Pharmacology \& Therapeutics, 25(5), 599-608.

23. Jun DW, Park HY, Lee OY, Lee HL, Yoon BC, Choi H S, Hahm JS, Lee MH, Lee DH, Kee C S. 2006. A population-based study on bowel habits in a Korean community: Prevalence of functional constipation and self-reported constipation. Digestive Diseases and Sciences, 51(8), 1471-7.

24. Kalat, JW. 2014. Introduction to Psychology (10th ed.). California: Cengage Learning.

25. Kline RB. 2010. Principles and practice of structural equation modeling (3rd ed.). New York: Guilford Publications.

26. Koloski NA, Jones M, Wai R, Gill RS, Byles J, Talley NJ. 2013. Impact of persistent constipation on health-related quality of life and mortality in older community-dwelling women. The American Journal of Gastroenterology, 108(7), 1152-8.

27. Kua EH, Ko SM. 1992. A questionnaire to screen for cognitive impairment among elderly people in developing countries. Acta Psychiatrica Scandinavica, 85(2), 119-22. 
28. Kua EH, Ko SM. 1995. Prevalence of dementia among elderly Chinese and Malay residents of Singapore. International Psychogeriatrics, 7(3), 439-46.

29. Kunduru L, Kim SM, Heymen S, Whitehead WE. 2015. Factors that affect consultation and screening for fecal incontinence. Clinical Gastroenterology and Hepatology, 13(4), 709-16.

30. Li MK, Lee TFD, Suen KPL. 2014. Complementary effects of auricular acupressure in relieving constipation symptoms and promoting disease-specific health-related quality of life: A randomized placebo-controlled trial. Complementary Therapies in Medicine, 22(2), 266-77.

31. Marquis P, De La Loge C, Dubois D, McDermott A, Chassany O. 2005. Development and validation of the patient assessment of constipation quality of life questionnaire. Scandinavian Journal of Gastroenterology, 40(5), 540-51.

32. Ministry of Women Family and Community Development. 2011. The National Policy for Older Persons. Available at https://www.kpwkm.gov.my/kpwkm/uploads/files/Dokumen/Dasar/Dasar Warga Emas_2011.pdf (accessed 15 November 2019).

33. Momtaz YA, Hamid TA, Yahaya N. 2009. The role of religiosity on relationship between chronic health problems and psychological well-being among Malay muslim older persons. Research Journal of Medical Sciences, 3(6), 188-93.

34. Momtaz YA, Ibrahim R, Hamid TA, Yahaya N. 2010. Mediating effects of social and personal religiosity on the psychological well being of widowed elderly people. OMEGA, 61(2), 145-62.

35. Müller-lissner S, Rykx A, Kerstens R, Vandeplassche L. 2010. A double-blind, placebocontrolled study of prucalopride in elderly patients with chronic constipation. Neurogastroenterology \& Motility, 22(9), 991-e255.

36. Müller-Lissner S, Tack J, Feng Y, Schenck F, Specht Gryp R. 2013. Levels of satisfaction with current chronic constipation treatment options in Europe: An internet survey. Alimentary Pharmacology and Therapeutics, 37(1), 137-45.

37. Nellesen D, Yee K, Chawla A, Lewis BE, Carson RT. 2013. A systematic review of the economic and humanistic burden of illness in irritable bowel syndrome and chronic constipation. Journal of Managed Care Pharmacy, 19(9), 755-64.

38. Nilsson J, Parker MG, Kabir ZN. 2004. Assessing health-related quality of life among older people in Rural Bangladesh. Quality of Life Research, 13(9), 1582.

39. Nour-Eldein H, Salama HM, Abdulmajeed AA, Heissam KS. 2014. The effect of lifestyle modification on severity of constipation and quality of life of elders in nursing homes at Ismailia city, Egypt. Journal of Family \& Community Medicine, 21(2), 100-6.

40. Nunnally J. 1978. Psychometric theory (2nd ed.). New York: McGraw-Hill.

41. Patimah AW, Lee YY, Siti Hawa A, Azidah AK, Dariah MY. 2017. Beliefs and behavioural responses to constipation among elderly Malays in north-eastern Peninsular Malaysia. Australian and New Zealand Continence Journal, 23(3), 76-83.

42. Pinto Sanchez MI, Bercik P. 2011. Epidemiology and burden of chronic constipation. Canadian Journal of Gastroenterology, 25(Suppl B), 11B-15B.

43. Polit DF, Beck CT. 2006. The content validity index: Are you sure you know what's being reported? critique and recommendations. Research in Nursing \& Health, 29(5), 489-97.

44. Polit DF, Beck CT. 2012. Nursing research: Generating and assessing evidence for 
nursing practice (9th ed.). Philadelphia: Wolters Kluwer Health.

45. Rockwood TH, Church JM, Fleshman JW, Kane RL, Mavrantonis C, Thorson AG, Wexner SD, Bliss D, Lowry AC. 2000. Fecal incontinence quality of life scale: Quality of life instrument for patients with fecal incontinence. Diseases of the Colon \& Rectum, 43(January), 9-16.

46. Shalmani HM, Soori H, Mansoori BK, Vahedi M, Moghimi-Dehkordi B, Pourhoseingholi MA, Norouzinia M, Zali MR. 2011. Direct and indirect medical costs of functional constipation: A population-based study. International Journal of Colorectal Disease, 26(4), 515-22.

47. Sun SX, Dibonaventura M, Purayidathil FW, Wagner J, Dabbous O, Mody R. 2011. Impact of chronic constipation on health-related quality of life, work productivity, and healthcare resource use: An analysis of the National Health and Wellness Survey. Digestive Diseases and Sciences, 56(9), 2688-95.

48. Szeinbach SL, Baran RW, Bratten J, Jones MP. 2009. Psychometric development and validation of the chronic constipation treatment satisfaction questionnaire (CTSAT-Q). Value in Health, 12(6), 1004-10.

49. Tabachnick BG, Fidell LS. 2007. Principal components and factor analysis. In S. Hartman (Ed.), Using multivariate statistics (5th ed., pp. 607-75). USA: Pearson Education, Inc.

50. Wang JY, Hart SL, Lee J, Berian JR, McCrea GL, Varma MG. 2009. A valid and reliable measure of constipation-related quality of life. Diseases of the Colon \& Rectum, 52(8), 1434-42.

51. Wong RKM, Drossman DA. 2010. Quality of life measures in irritable bowel syndrome. Expert Review of Gastroenterology \& Hepatology, 4(3), 277-84.

52. Zainudin A. 2014. A handbook on SEM for academicians and practitioners. Selangor: MPWS Rich Publication.

53. Zainudin A. 2015. SEM made simple. Selangor: MPWS Rich Publication. 
Figure 1

Development and validation of the scale 


\section{Phase 1: Items generation}

No. of items $=74$

Temporary domains: 7

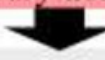

Restructure:

a) Content validity:

No. of items $=43$

b) Face validity:

No. of items $=40$

Phase 2: Items reduction and establishment of factor structure

Data analysis: exploratory factor analysis (EFA)

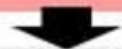

Restructure:

a) No. of items $=27$

b) No. of factors $=8$

Phase 3: Confirmation of the factor structure and items

Data analysis: Confirmatory factor analysis (CFA)

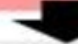

Restructure:

a) No. of items $=22$

b) No. of factors $=7$

Figure 1 Development and validation of the scale 
Figure 2

The measurement model for pooled-CFA

RMSEA $=0.04, \mathrm{CFI}=0.961, \mathrm{TLI}=0.952, \mathrm{chisq} / d f=1.44$ 
1

2

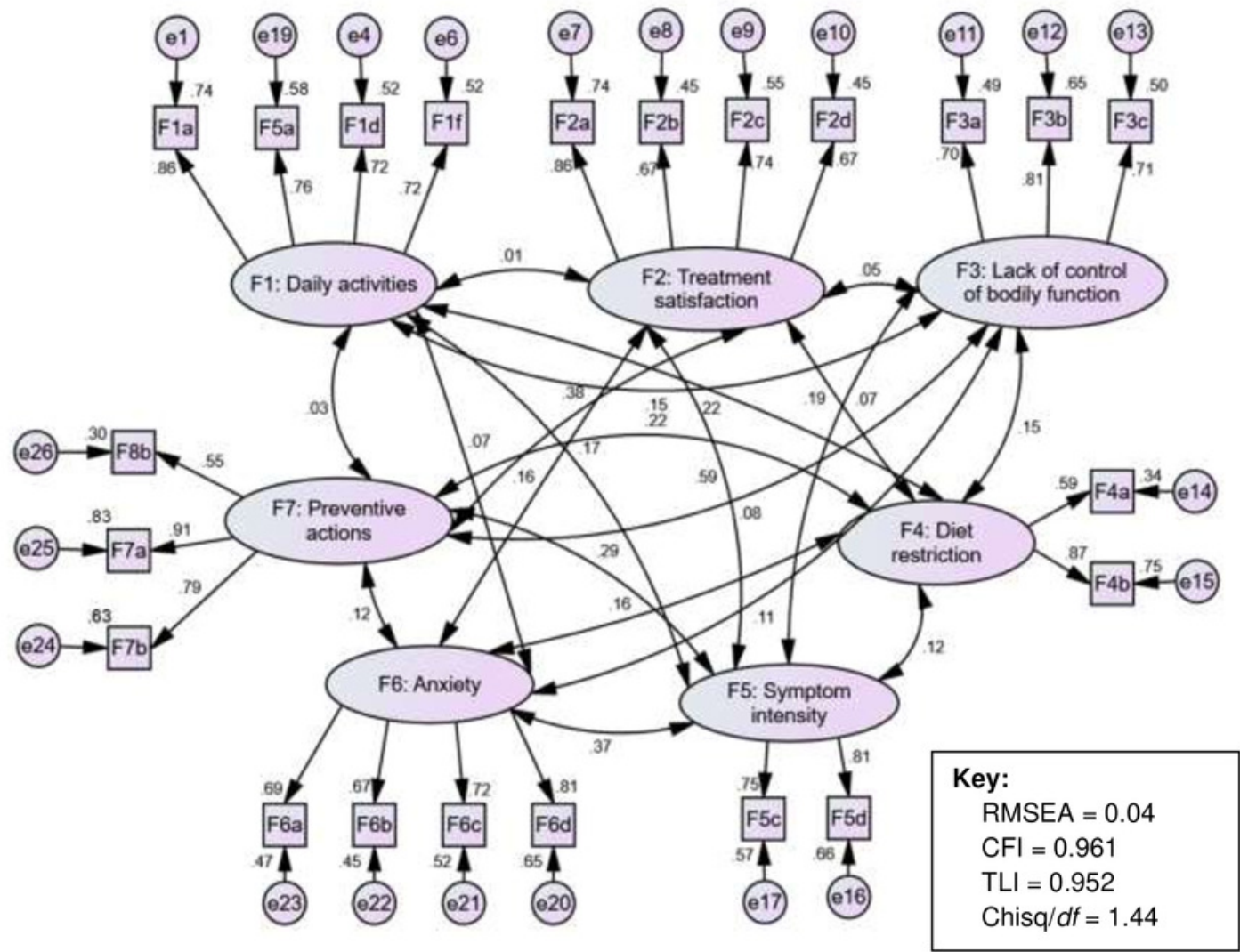

3

5

6

Figure 2 The measurement model for pooled-CFA.

8

9

10

11

12

13

14

15 


\section{Table 1 (on next page)}

Characteristics participants of the study

Notes: $N=$ number of participants; $S D=$ standard deviation. 
1 Table 1. Characteristics participants of the study

2

\begin{tabular}{lll}
\hline Characteristics & $N(\%)$ & Mean $\pm S D$ \\
\hline Age & $281(59.8)$ & \\
$60-69$ & $157(33.4)$ & \\
$70-79$ & $32(6.8)$ & \\
80 and above & & \\
Sex & $219(46.4)$ & \\
Men & $251(53.6)$ \\
Women & \\
Educational level & $136(28.9)$ \\
Never to school & $30(6.4)$ \\
Informal school & $158(33.6)$ \\
Primary school & $134(28.5)$ \\
Secondary school & $12(2.6)$ & \\
College/university & \\
Employment status & $133(28.3)$ \\
Employed & $46(9.8)$ \\
Pensioner & $291(61.9)$ & \\
Unemployed & & \\
General health status & & \\
Poor to very poor & & \\
Moderate & & \\
Good to very good & & \\
\hline & & \\
\end{tabular}

3 Notes. $N=$ number of participants; $S D=$ standard deviation 


\section{Table 2 (on next page)}

\section{Exploratory factor solution for 27 items}

Notes: F1 = daily activities; F2 = treatment satisfaction; F3 = lack of control of bodily function; F4 = diet restriction; F5 = symptom intensity; F6 = anxiety; F7 = dietary fiber intake; F8 = fluid intake. 
1 Table 2. Exploratory factor solution for 27 items

2

\begin{tabular}{|c|c|c|c|c|c|c|}
\hline $\begin{array}{l}\text { Factor } \\
\text { (F) }\end{array}$ & Items & $\begin{array}{l}\text { Factor } \\
\text { loading }\end{array}$ & Communality & $\begin{array}{l}\text { Item-total } \\
\text { correlation }\end{array}$ & $\begin{array}{c}\text { Cronbach's } \\
\text { alpha if item } \\
\text { deleted }\end{array}$ & $\begin{array}{c}\text { Cronbach's } \\
\text { alpha }\end{array}$ \\
\hline \multirow{6}{*}{ F1 } & F1a & 0.66 & 0.47 & 0.57 & 0.77 & \multirow{6}{*}{0.80} \\
\hline & F1b & 0.65 & 0.40 & 0.54 & 0.78 & \\
\hline & F1c & 0.55 & 0.40 & 0.53 & 0.78 & \\
\hline & F1d & 0.54 & 0.58 & 0.58 & 0.77 & \\
\hline & F1e & 0.59 & 0.49 & 0.53 & 0.78 & \\
\hline & F1f & 0.60 & 0.53 & 0.61 & 0.76 & \\
\hline \multirow{4}{*}{$\mathrm{F} 2$} & F2a & 0.88 & 0.76 & 0.79 & 0.84 & \multirow{4}{*}{0.88} \\
\hline & $\mathrm{F} 2 \mathrm{~b}$ & 0.82 & 0.69 & 0.76 & 0.85 & \\
\hline & $\mathrm{F} 2 \mathrm{c}$ & 0.94 & 0.84 & 0.83 & 0.82 & \\
\hline & $\mathrm{F} 2 \mathrm{~d}$ & 0.49 & 0.59 & 0.63 & 0.90 & \\
\hline \multirow{3}{*}{ F3 } & F3a & 0.59 & 0.51 & 0.55 & 0.79 & \multirow{3}{*}{0.79} \\
\hline & F3b & 0.86 & 0.67 & 0.67 & 0.66 & \\
\hline & $\mathrm{F} 3 \mathrm{c}$ & 0.65 & 0.58 & 0.67 & 0.67 & \\
\hline \multirow{2}{*}{ F4 } & F4a & 0.76 & 0.63 & 0.64 & - & \multirow{2}{*}{0.78} \\
\hline & $\mathrm{F} 4 \mathrm{~b}$ & 0.77 & 0.66 & 0.64 & - & \\
\hline \multirow{4}{*}{ F5 } & F5a & 0.45 & 0.39 & 0.43 & 0.59 & \multirow{4}{*}{0.66} \\
\hline & $\mathrm{F} 5 \mathrm{~b}$ & 0.58 & 0.43 & 0.49 & 0.55 & \\
\hline & $\mathrm{F} 5 \mathrm{c}$ & 0.68 & 0.53 & 0.49 & 0.56 & \\
\hline & F5d & 0.55 & 0.36 & 0.35 & 0.64 & \\
\hline \multirow{4}{*}{ F6 } & F6a & 0.54 & 0.48 & 0.52 & 0.72 & \multirow{4}{*}{0.76} \\
\hline & F6b & 0.53 & 0.34 & 0.45 & 0.75 & \\
\hline & F6c & 0.58 & 0.57 & 0.56 & 0.69 & \\
\hline & F6d & 0.63 & 0.74 & 0.69 & 0.61 & \\
\hline \multirow{2}{*}{ F7 } & F7a & 0.96 & 0.87 & 0.73 & - & \multirow{2}{*}{0.84} \\
\hline & $\mathrm{F} 7 \mathrm{~b}$ & 0.75 & 0.73 & 0.73 & - & \\
\hline \multirow{2}{*}{ F8 } & F8a & 0.96 & 0.82 & 0.56 & - & \multirow{2}{*}{0.70} \\
\hline & $\mathrm{F} 8 \mathrm{~b}$ & 0.48 & 0.45 & 0.56 & - & \\
\hline
\end{tabular}

3 Notes. F1 = daily activities; F2 = treatment satisfaction; F3 = lack of control of bodily function;

$4 \quad$ F4 = diet restriction; F5 = symptom intensity; F6 = anxiety; F7 = dietary fiber intake; F8 = fluid 5 intake.

6

7

8 


\section{Table 3 (on next page)}

The new version of the Elderly-Constipation Impact Scale (E-CIS)

Notes: $\mathrm{F}=$ factor; $\mathrm{CR}=$ composite reliability; $\mathrm{AVE}=$ average variance extracted 
1 Table 3. The new version of the Elderly Constipation Impact Scale (E-CIS)

\begin{tabular}{|c|c|c|c|c|}
\hline Factor/Items & $\begin{array}{l}\text { Factor } \\
\text { loading }\end{array}$ & $\begin{array}{c}\text { Cronbach's } \\
\text { alpha }\end{array}$ & $\mathrm{CR}$ & AVE \\
\hline F1: Daily activities & & 0.85 & 0.851 & 0.590 \\
\hline F1a I feel tired after defecation & 0.86 & & & \\
\hline F5a I feel depressed when I want to defecate & 0.76 & & & \\
\hline F1d The constipation interrupt my daily activity & 0.72 & & & \\
\hline $\begin{array}{l}\text { F1f I feel interrupted to pray because of the } \\
\text { constipation }\end{array}$ & 0.72 & & & \\
\hline F2: Treatment satisfaction & & 0.82 & 0.828 & 0.548 \\
\hline $\begin{array}{l}\text { F2a I am satisfied with the effectiveness of the } \\
\text { treatment }\end{array}$ & 0.86 & & & \\
\hline $\begin{array}{l}\text { F2b I am satisfied with the methods used for the } \\
\text { constipation treatment }\end{array}$ & 0.67 & & & \\
\hline $\begin{array}{l}\text { F2c I am satisfied that I get to defecate as I wish for } \\
\text { after the treatment }\end{array}$ & 0.74 & & & \\
\hline $\begin{array}{l}\text { F2d I am confident that constipation will be easy to } \\
\text { treat if it recurs }\end{array}$ & 0.67 & & & \\
\hline F3: Lack of control of bodily function & & 0.78 & 0.783 & 0.546 \\
\hline F3a My body feels sick as if I were to have a fever & 0.70 & & & \\
\hline F3b The effects of my constipation treatment is slow & 0.81 & & & \\
\hline F3c I feel that I fail to control my constipation & 0.71 & & & \\
\hline F4: Diet restriction & & 0.66 & 0.699 & 0.546 \\
\hline $\begin{array}{l}\text { F4a Constipation makes me control the quantity of } \\
\text { food taken }\end{array}$ & 0.59 & & & \\
\hline $\begin{array}{l}\text { F4b Constipation makes me choose the type of food } \\
\text { taken }\end{array}$ & 0.87 & & & \\
\hline F5: Symptom intensity & & 0.76 & 0.761 & 0.614 \\
\hline F5c I extract the feaces out & 0.75 & & & \\
\hline F5d I strain strongly during defecation & 0.81 & & & \\
\hline F6: Anxiety & & 0.81 & 0.815 & 0.525 \\
\hline $\begin{array}{l}\text { F6a I think that my intestinal function has been } \\
\text { damaged }\end{array}$ & 0.69 & & & \\
\hline $\begin{array}{l}\text { F6b I fear that there will be blood coming out from } \\
\text { the anus when I want to defecate }\end{array}$ & 0.67 & & & \\
\hline F6c I fear that the anus will come out if I strain & 0.72 & & & \\
\hline $\begin{array}{l}\text { F6d I fear that the anus will tear because of the big } \\
\text { feaces }\end{array}$ & 0.81 & & & \\
\hline F7: Preventive actions & & 0.83 & 0.804 & 0.587 \\
\hline $\begin{array}{l}\text { F7a Constipation makes me take more vegetables in } \\
\text { my diet }\end{array}$ & 0.91 & & & \\
\hline $\begin{array}{l}\text { F7b Constipation makes me take more fruits in my } \\
\text { diet }\end{array}$ & 0.79 & & & \\
\hline F8b Constipation makes me drink a lot of drinking & 0.55 & & & \\
\hline
\end{tabular}


water

2 Notes. $\mathrm{F}$ = factor; $\mathrm{CR}=$ composite reliability; $\mathrm{AVE}=$ average variance extracted.

3

4

5

6 